\title{
The Relationship Between Neurotic Leadership Styles, Transformational Leadership, Emotional Intelligence, and Worker Attitudes
}

\author{
Al Bellamy \\ College of Technology \\ Eastern Michigan University \\ Ypsilanti, Michigan \\ Allen Bellamy \\ Department of Psychology \\ University of Michigan - Flint
}

doi: 10.19044/esj.2016.v12n22p68 URL:http://dx.doi.org/10.19044/esj.2016.v12n22p68

\begin{abstract}
This study explored the relationships between neurotic leadership styles, transformational leadership, the emotional intelligence of supervisors, employee job satisfaction, and employee perceptions of leadership effectiveness. The primary objective of this exploratory investigation consisted of determining the extent to which scales measuring neurotic leadership are correlated with extant organizational processes such as leadership and job satisfaction. The study, utilizing a survey was conducted in five law enforcement agencies located in Southeast Michigan. The sample size is 143 police officers. Results of the study reveal significant correlations between the neurotic leadership scales and the other primary factors within the study. It further revealed that the type and strength of the relationships varied across the law enforcement agencies. This latter finding provides strong support for the need to develop empirical studies that integrate psychodynamic and organizational levels analyses.
\end{abstract}

Keywords: Neurotic Leadership, Transformational Leadership, Emotional Intelligence, Job Satisfaction

\section{Introduction}

The purpose of this study was to explore the ways in which measurements of neurotic leadership style correlate with measures of leader emotional intelligence, transformational leadership, perceptions of leadership effectiveness, and employee work attitudes within law enforcement agencies. From an empirical perspective, neurotic leadership is a relatively new and 
emerging concept within the lexicon of organizational leadership. Neurotic leadership lies within the framework of psychodynamic theory that applies psychoanalytic theories to the study of organizations. (Motamedi, 2006; Stacey, 2005; Czander, 1993; DeBoard, 1978; Kets, de Vries, 1991; 1984). This framework attempts to link intrapsychic phenomena with various organizational processes such as strategy making, culture, and leadership styles. (Kets de Vries and Millier, 1984; Neuman and Hirschorn, 1999). Much of the literature extending from this school of thought link psychopathology to organizational dysfunctions (Sievers, 1999; Kets deVries, 1989)

A shortcoming of the psychoanalytic approach to leadership is that very few investigations have been conducted that have empirically tested the influence of neurotic leadership on organizational processes. Most, if not all of the evidence brought forth within the literature is anecdotal and conjecture.

Our approach within this study has been to construct ordinal measurements of leadership style based upon generic definitions of certain neurotic behaviors. We then attempted to examine the extent to which these scales relate to other leadership styles and employee job satisfaction and perceptions of their supervisors leadership effectiveness. Although most of the theoretical literature alludes to the impact of neurotic leadership on organizational functioning, our primary objective is to first determine whether or not this concept is empirically applicable to organizational studies.

The paper will proceed as follows:

1. We will first define neurotic leadership. We will elucidate upon four of the neurotic leadership styles that has been presented within the literature and for which this present study has attempted to operationalize.

2. A discussion related to the two primary leadership factors that was used to examine the explanatory fecundity of our neurotic leadership measure will be presented. These two factors are transformational leadership and emotional intelligence.

3. The paper will then proceed to describe the research hypotheses, research methodology, statistical results and implications for future research.

\section{Review of primary research variables \\ Neurotic Leadership Styles}

The focal point of the academic dialogue concerning neurotic leadership has been the idea that organizations portray similar behavioral pathologies as those shown among individuals receiving psychoanalytic counseling (Kets De Vries \& Miller, 1984). Furthermore, it is the psychological pathologies of individuals in power that permeate the 
organization with their personality orientation. For example, it is alleged that paranoid managers tend to create organizational cultures and processes that are reminiscent of their paranoia.

This study utilized four categories of neuroticism as presented within the work of Kets DeVries and Miller (1984). They are paranoid, compulsive, depressive, and narcissistic. De Vries and Miller presented the idea that these unconscious constructs represent or rather, influence leadership styles. This makes the assumption that unconscious psychological phenomena are validly connected to behavioral expressions_such as the behavior of leaders. It could be argued of course, that the concept of organizational culture is really the construct that is being referenced and that the idea of neuroticism, given its high tenability is better understood through this idea. However, we feel that to make such a leap is creating a reified framework of analyses. That is, culture does not exist independently of its practice. Rather, it extends from intrapersonal and interpersonal organizational processes. Individuals, who certainly possess a personality orientation in turn enacted these processes. Most importantly, the integration of psychodynamic theory with organizational analyses is contingent upon creating methodological tools appropriate to the study of so-called unconscious phenomena and various organizational processes. We have attempted to develop a leadership scale (NL) that measures specific neurotic tendencies as identified within this literature. The scales focuses on behavioral processes of leaders that allude to specific neurotic orientations rather than the much more complex construct of neuroses itself. A description of these styles will now be presented.

The Paranoid style refers to a leader who:

Is suspicious and exhibits mistrust of others.

Is very secretive about things related to the work unit.

Uses his/hers employees to find out what others are doing.

Creates an atmosphere of apathy among employees.

The Compulsive style is one that:

Shows a preoccupation with trivial details before making a decision.

Overly concerned with employees submitting to organizational rules and procedures

Appears to be obsessed with controlling people.

Is overly concerned with individual rank and status.

The Depressive style of leadership:

Is one that suppresses new ideas of employees.

Does not encourage people to "think out of the box".

Does not look for new ways of doing things to improve organizational performance.

Insists on managing by things according to the "book". 
The Dramatic style is one that:

Excessively expresses their emotions.

Draws attention to themselves.

Appears to have a craving for excitement

Is overly concerned with impressing others.

Kets DeVries and Miller (1991) present an overall personality syndrome for each of these styles. They are described within the following chart:

\section{Chart A}

\section{Summary of Neurotic Tendencies}

\begin{tabular}{llll}
\hline Paranoid & Compulsive & Depressive & Dramatic \\
\hline $\begin{array}{l}\text { "I cannot really trust } \\
\text { anybody; a menacing force } \\
\text { exists that is out to get me" }\end{array}$ & $\begin{array}{l}\text { "I don't want to be at } \\
\text { the mercy of events; } \\
\text { have to master and control } \\
\text { all things affecting me" }\end{array}$ & $\begin{array}{l}\text { "It is hopeless to change } \\
\text { the course of events in my } \\
\text { life; I am just not good } \\
\text { enough" }\end{array}$ & $\begin{array}{l}\text { "I want to get attention } \\
\text { people who count in } \\
\text { my life" }\end{array}$ \\
\hline
\end{tabular}

\section{Emotional Intelligence}

There appears to be a theoretical and practical affinity between the concepts of neuroticism and emotions. A neurotic orientation as summarized within the above descriptions and chart is directly connected to emotions. In fact all behaviors, including those found in organizations are related to emotions. Organizational science in previous years has emphasized rational structures and processes. Subsequently, until recently, the study of emotions within organizational science has been ignored. (Domagalski, 1999; Finemann, 1993, Flam, 1993) Management has constantly been advised to be "professional" and to leave their emotions at the door. However, there has been recent emphasis on the idea that emotions are in fact the foundation of so-called rational behavior. (Ashforth \& Humphrey, 1995, Goleman, 1996). An emerging concept that reflects this thought is emotional intelligence. Emotional intelligence (EQ) is defined as:

"the ability to monitor one's own and other feelings and

emotions, to discriminate among them and to use this information to

guide one's thinking and actions." (Mayer and Salovey, 1990. p189).

EQ and so-called rational cognitive processes are not opposing competencies, but rather EQ serves as a base that fecundates these “intelligence" factors. As Mayer (1990) et al state:

"emotional intelligence arises from a productive union of the cognitive and 
about

emotion systems. The cognitive system carries out abstract reasoning

emotions, while the emotion system enhances cognitive capacity. More specifically, individuals high in emotional intelligence have the ability to perceive, understand, and manage emotions, on the one hand, and to allow

emotions to facilitate their thought, on the other.” (p. 132).

Within this context of thought extreme neurotic leadership behaviors can be seen as having low degrees of emotional intelligence. This idea underlies the definitions of the four sub dimensions of emotional intelligence that follow. Four facets of emotional intelligence have been identified in the literature. They are: self-awareness, empathy, managing relationships, and emotion management.

Self awareness pertains to the cognitive ability to accurately appraise one's own emotions, feelings, and behaviors. It also pertains to expressing one's feelings. In short, this dimension references an individual's ability to selfreflect and understand their emotions. Reflection facilitates the use of emotional information for making judgments and decisions (George, 2000).

Empathy refers to appraising the emotions of others. In social psychological terms (Mead, 1930) it consists of "taking the role of the other" and experiencing as well as understanding a persons emotions from their perspective as well as your own

Managing relationships refers to the ability to perceive and understand the emotions and behaviors of others and to modify one's own emotional response to such an understanding. It is the recursive interpretation of self and other's emotions. An individual who is intelligent on this dimension would be able to effectively handle conflict and to affect employee behavior in positive ways.

Emotion management refers to the ability to regulate emotions and behaviors according to their situational appropriateness. This requires cognitive reflection on the potential ways in which an emotional behavior will affect and be affected within a specific situation.

We propose that extreme neurotic behaviors on the part of the leader will reflect parallel inabilities on each of the above EQ dimensions. That is, higher levels of NL will be associated with lower levels of emotional intelligence.

\section{Transformational Leadership}

Transformational leadership (TL) refers to the ability of a manager/supervisor to motivate followers to higher levels of personal and professional development (Bass \& Avolio, 1994). Emotional intelligence has been cited as an important factor for enhancing leadership effectiveness 
because of its emphasis on people and interpersonal relationships (Caruso, Mayer and Salovey, 2002). We examined the question as to whether the degree of neuroticism exhibited by leaders would negatively influence their ability to be transformative. The four facets of transformational leadership are idealized influence, inspirational leadership, intellectual stimulation, and individualized stimulation.

Idealized influence refers to demonstrating high standards of conduct, determination and far-sightedness.

Inspirational leadership is one that challenges employees to go far beyond the expectations of their job positions through prosocial and collective action.

Intellectual stimulation refers to the ability to promote innovation and creativity among employees by getting them to challenge old assumptions and approaching old problems from fresh frames of references.

Individualized consideration pertains to the ability to develop employees through mentoring. This requires an understanding of the employee needs.

In essence, we expect that neurotic leader behaviors will interfere with supervisors and managers ability to be transformative.

\section{Research methods}

\section{Sample}

Data for this study was collected from four law enforcement agencies within the southeastern area of Michigan. Two precincts from one large agency participated within the study yielding a total of five organizations. Our University conducts a comprehensive Staff and Command training program for law enforcement supervisors. Several of these students agreed to participate in our study. Specific departments within the agencies that these supervisors are employed were selected on their availability. A total of 143 law enforcement officers and administrators were surveyed utilizing this process. A total sampling was conducted within each department. Four individuals out of a possible 147 declined to participate in the survey. A summary of the sampling demographics of each organization is presented within the chart below.

\section{Chart B}

Summary of Sample

$\begin{array}{lll}\text { Type of } & \text { Agency } & \text { Number of } \\ \text { Agency } & \text { Size } & \text { Survey Participants }\end{array}$

Agency One

City Police

250

41

Precinct

Department 


$\begin{array}{llcc}\begin{array}{l}\text { Agency One } \\ \text { Gang Squad }\end{array} & \begin{array}{l}\text { City Police } \\ \text { Department }\end{array} & 61 & 20 \\ \text { Agency Three } & \begin{array}{l}\text { City Police } \\ \text { Department }\end{array} & 276 & 32 \\ \text { Agency Four } & \begin{array}{l}\text { County } \\ \text { Sheriff }\end{array} & 115 & 21 \\ \text { Agency Five } & \begin{array}{l}\text { City Police } \\ \text { Department }\end{array} & 177 & 29 \\ & & \text { Total } & \mathbf{1 4 3}\end{array}$

Participants that were selected from each agency were from units in which officers reported to just one supervisor and who only worked one shift. It is common for employees in law enforcement agencies to report to more than one supervisor. The leadership variables within this study were measured from employee's description of their supervisor's behavior.

\section{Measurements}

A survey questionnaire was constructed to measure each of the variables examined within this study. The following is a description of the survey.

Neurotic Leadership Styles. Utilizing the conceptual description of the neurotic styles described above, ordinal scales were developed that consisted of items reflecting these conceptual definitions. Employees were asked to assess the behaviors of their immediate supervisor. Each scale consisted of five anchors and scale points ranging from strongly agree to strongly disagree. A value of five was give to a strongly agree response and a value of one was given for a strongly disagree response. Four items were created for each of the four neurotic leadership styles. A copy of these scales is presented within Appendix A.

Emotional Intelligence. This variable was measured using a scale developed by Tapia \& Burry-Stock (1998). Their scale consisted of 41 items measuring the following factors: empathy, reflection on feelings, handling relationships, and self-control. We used a modified scale of this instrument consisting of 32 items: eight items for each factor. Participants were asked to evaluate their immediate supervisor on each of the 32 items. This is a modification to the Tapia and Burry-Stock scale, which requires supervisors to evaluate themselves. Subordinate ratings of their supervisor's EQ are believed to be a more valid measurement than supervisor self-ratings (Casey \& Mayer, 2000). A five point and five anchor response scale was utilized that range from "never" to "always like her/him". A score of one was attached to a never response and a score of five was given to a response of always like her/him. Higher scores represent a higher level of supervisory EQ. 
Transformational Leadership. The four facets of transformational leadership (TL) examined within this study were measured by the Multifactor Leadership Questionnaire (MLQ) rater form developed by Bass and Avolio (1994). Each facet consisted of 4 items with four scale points in which employees were asked to describe the leadership behavior of their supervisor. A five point and five anchor response scale was utilized that range from "not at all" to "frequently, if not always". A score of one was attached to a" not at all” response and a score of five was given to a response of frequently. Higher scores represent a higher level on TL. Code names that are used in the statistical tables are as follow:

Intellectual stimulation: Intellec.

Idealized influence: Influence.

Inspirational leadership: Inspire

Individualized consideration: Consid.

Perceived Leadership Effectiveness. The study utilized three outcome factors from the MLQ consisting of the rater's perceptions of 1 . Their satisfaction with their supervisor's effectiveness (4 items, coded as "effectiveness,") 2. Their satisfaction with their supervisor's leadership behavior (2 items, coded as " Tlsat") and, 3. The extent that they perceive their supervisor as influencing them to apply extra effort on their jobs (3 items, coded as "extra effort"). These three items were combined to form one scale entitled "outcome". The same response scale and scoring that was applied to the MLQ was utilized for these variables.

Job Satisfaction. Job satisfaction was measured by a four item scale that inquired of the respondent's attitudes regarding their job, supervisor, pay and co-workers. Each item has five scale points and response anchors ranging from agree to disagree. A score of one was given for a disagree response and a score of five was given for an agree response.

Chart $C$ describes the alpha reliabilities of each of the scales utilized within this study.

Chart C.

Alpha Reliabilities of Measurements

\section{Neurotic Leadership}

Entire Scale

Paranoid Factor .52

Compulsive Factor

Depressive Factor

Compulsive Factor 


\section{Emotional Intelligence \\ Entire Scale $\quad .91$ \\ Empathy Factor $\quad .63$ \\ Reflection Factor $\quad .75$ \\ Self Control Factor $\quad .75$ \\ Relationships Factor $\quad .88$ \\ Transformational Leadership \\ Entire Scale \\ Idealized Influence $\quad .74$ \\ Intellectual stimulation $\quad .85$ \\ Inspirational motivation $\quad .92$ \\ Individual consideration $\quad .89$ \\ Leadership Effectiveness \\ Effectiveness $\quad .88$ \\ Tlsat: $\quad .91$ \\ Extra effort $\quad .90$}

Job Satisfaction

.89

\section{Research Hypotheses}

Hypothesis 1. A negative correlation exists between each of the four neurotic leadership styles and the overall measurement of emotional intelligence.

Hypothesis 2. A negative correlation exists between each of the four neurotic leadership styles and each of the four dimensions of emotional intelligence.

Hypothesis 3. A negative correlation exists between each of the four neurotic leadership styles and the overall measurement of transformational leadership.

Hypothesis 4. A negative correlation exists between each of the four neurotic leadership styles and each of the four dimensions of transformational leadership

Hypothesis 5. A negative correlation exists between each of the four neurotic leadership styles and employee job satisfaction.

Hypothesis 6. A negative correlation exists between each of the four neurotic leadership styles and employees perception of leadership effectiveness

We will test our hypotheses by utilizing bivariate correlation analyses. This procedure is very appropriate to exploratory analyses. 


\section{Research Question}

1. To what extent do the correlations cited above differ among the law enforcement agencies included within this present study?

\section{Results}

Hypothesis 1: "A negative correlation exists between each of the four neurotic leadership styles and the overall measurement of emotional intelligence".

Table I. reveals that there are no statistically significant correlations between the neurotic leadership styles and the overall measurement of emotional intelligence. This hypotheses is not supported.

Hypotheses 2: “A negative correlation exists between each of the four neurotic leadership styles and each of the four dimensions of emotional intelligence."

As revealed in Table I., only one of the correlations (control) has a statistically significant correlation. This hypothesis is not supported.

Hypotheses 3: "A negative correlation exists between each of the four neurotic leadership styles and the overall measurement of transformational leadership”.

This hypothesis is not supported by this study.

Hypotheses 4: “ A negative correlation exists between each of the four neurotic leadership styles and each of the four dimensions of transformational leadership".

The results in Table I show that this hypothesis is only supported for the dramatic leadership style.

Hypotheses 5: "A negative correlation exists between each of the four neurotic leadership styles and job satisfaction and perceived leadership effectiveness".

As shown in Table I, each of the neurotic leadership styles is correlated with employee job satisfaction. This hypothesis is supported.

Hypothesis 6: "A negative correlation exists between each of the four neurotic leadership styles and perceived leadership effectiveness".

No statistically significant correlations are revealed between neurotic leadership styles and perceived leadership effectiveness. This hypothesis is not supported.

The results in relation to the total sample do not lend strong support to the idea that neurotic leadership is related to other leadership styles, including perceived leadership effectiveness. On the other hand, strong support is given in regards to employee job satisfaction. In essence, the data reveal that neurotic leadership behaviors negatively affect employee work attitudes. This in and of itself is an important finding since it adds to our understanding an additional factor affecting worker attitudes. On the other hand, the results 
for the entire sample indicate that NL does not influence employee's perception of their supervisor's effectiveness.

Research Question: To what extent do the correlations between the neurotic leadership styles, transformational leadership, emotional intelligence, employee job satisfaction, and perceived leadership effectiveness, differ among the law enforcement agencies included within this present study?

The data, when examined separately within each of the law enforcement agencies, reveal significantly different results in comparison to those for the entire sample. Tables 1 thru 6 present the results according to law enforcement agency. Given the large number of possible statistical comparisons, we will make comments on those that appear to be significant. To begin with, the results shown for the entire sample imply that there is no, or very little correlation between the neurotic leadership factors and emotional intelligence. However, the very opposite is revealed when reviewing these correlations within each agency. Statistically significant correlations are shown among many of the relationships for every agency. The degree of association as well as the EQ dimensions that NL correlates with varies among the agencies.

Agency One reveals the least number of correlations, while Agency Four shows the most number of correlations. In fact, Agency One reveals the least number of correlations for all of the relationships examined within this study, while Agency Four reveals the largest number of correlations. Overall, the strongest, as well as the largest number of correlations are shown among the paranoid and depressive neurotic factors.

In regards to transformational leadership, the results again show correlations to NL within the agencies whereas none was shown for the total sample. Very strong and statistically significant correlations are particularly revealed within agencies four, five and two. Once again, the strength and significance of the correlation with specific TL factors vary according to the agency. For example, within Agencies One, Two and Three, there are no significant correlations between $\mathrm{Tl}$ and the compulsive factor. However, Agencies Four and Five both show significant relationships for the inspiration and consideration TL factors. Further, Agency Three reveals correlations only for the depressive neurotic factor.

The correlations between neurotic leadership styles, employee job satisfaction, and employee's perception of leadership effectiveness, similar to TL and EQ, vary according to agency. Agency One shows the least number of correlations; the relationship between the depressive factor and leadership effectiveness. Comparatively, Agency Four reveals significant and relatively strong correlations among all of the NL, job satisfaction, and leadership effectiveness factors. 
Table 1

Bivariate Correlations of Neurotic Leadership Factors with Factors of Emotional Intelligence, Transformational Leadership, Job Satisfaction, and Perceived Leadership Effectiveness for Entire Sample

$\mathrm{N}=143$

\begin{tabular}{lllll}
\hline & Paranoid & Compulsive & Depressive & Dramatic \\
\hline EQ & & & & \\
Entire Scale & -.095 & -.121 & -.101 & -.040 \\
Empathy & -.134 & -.024 & -.092 & -.040 \\
Reflect & -.096 & -.152 & -.038 & -.089 \\
Relate & -.031 & -.033 & -.013 & -.011 \\
Control & -.061 & $-.146^{*}$ & -.072 & -.013 \\
& & & & \\
TL & & & & -.135 \\
Entire Scale & -.121 & -.052 & -.007 & -.091 \\
Intellec & $-.193^{*}$ & -.050 & -.050 & $-.151^{*}$ \\
Influence. & -.022 & -.063 & -.014 & $-.165^{*}$ \\
Inspire & -.094 & -.008 & -.008 & $-.161^{*}$ \\
Consid. & -.113 & -.002 & -.012 & \\
Job Satisfaction & $-.365^{*} *$ & $-.311^{*} *$ & $-.389 * *$ & -.081 \\
Outcome & -.110 & -.087 & -.040 & \\
\hline
\end{tabular}

${ }^{*} \mathrm{p} \leq .05 \quad * * \mathrm{p} \leq .00$

Table 2

Bivariate Correlations of Neurotic Leadership Factors with Factors of Emotional Intelligence, Transformational Leadership, Job Satisfaction, and Perceived Leadership Effectiveness for Agency One.

$\mathbf{N}=\mathbf{2 0}$

\begin{tabular}{lllll}
\hline & Paranoid & Compulsive & Depressive & Dramatic \\
\hline EQ & & & & \\
Entire Scale &.$- .429 * *$ & -.044 & $-.329 *$ & -.172 \\
Empathy & $-.312^{*}$ & -.095 & $-.265^{*}$ & -.110 \\
Reflect & $-.562^{* *}$ & -.096 & $-.336^{*}$ & -.191 \\
Relate & $-.397^{*}$ & -.136 & $-.356^{*}$ & -.048 \\
Control & $-.614^{*}$ & -.241 & -.029 & -.226 \\
& & & & \\
TL & & & & \\
Entire Scale & -.126 & -.143 & $-.384^{*}$ & $-.276^{*}$ \\
Intellec & -.077 & -.036 & -.005 & -.258 \\
Influence. & -.166 & -.245 & -.204 & -.280 \\
Inspire & -.111 & -.106 & $-.343^{*}$ & $-.324^{*}$ \\
Consid. & -.009 & -.197 & $-.408^{*}$ & $-.380^{*}$ \\
Job Satisfaction & -.065 & -.056 & -.203 & -.401 \\
Outcome & -.087 & -.036 & $-.394^{*}$ & -.017 \\
\hline
\end{tabular}

${ }^{*} \mathrm{p} \leq .05 \quad * * \mathrm{p} \leq .00$ 
Table 3

Bivariate Correlations of Neurotic Leadership Factors with Factors of Emotional Intelligence, Transformational Leadership, Job Satisfaction, and Perceived Leadership Effectiveness for Agency Two

$\mathrm{N}=\mathbf{4 1}$

\begin{tabular}{lllll}
\hline & Paranoid & Compulsive & \multicolumn{1}{c}{ Depressive } & Dramatic \\
\hline EQ & & & & \\
Entire Scale & $-.518^{* *}$ & -.013 & $-.552^{* *}$ & $-.260^{*}$ \\
$\quad$ Empathy & $-.431^{*}$ & -.014 & $-.430^{*}$ & -.110 \\
Reflect & $-.408^{*}$ & -.176 & $-.503^{*}$ & -.137 \\
Relate & $-.380^{*}$ & -.018 & $-.370^{*}$ & -.233 \\
Control & & & & \\
TL & & & & \\
Entire Scale & $-.483^{*}$ & -.080 & $-.633^{* *}$ & $-.478^{*}$ \\
Intellec & $-.407^{*}$ & -.075 & $-.468^{*}$ & $-.429^{*}$ \\
Influence. & $-.434^{*}$ & -.019 & $-.570^{* *}$ & $-.390^{*}$ \\
Inspire & $-.495^{*}$ & -.088 & $-.589^{* *}$ & $-.378^{*}$ \\
Consid. & $-.354^{*}$ & -.106 & $-.542^{* *}$ & $-.507^{* *}$ \\
& & & & \\
Job Satisfaction & -.079 & -.009 & -.157 & -.011 \\
Outcome &.$- .492^{*}$ & -.075 & $-.662^{* *}$ & $-.462^{* *}$ \\
\hline
\end{tabular}

${ }^{*} \mathrm{p} \leq .05 \quad * * \mathrm{p} \leq .00$

Table 4

Bivariate Correlations of Neurotic Leadership Factors with Factors of Emotional Intelligence, Transformational Leadership, Job Satisfaction, and Perceived Leadership Effectiveness for Agency Three $\mathbf{N}=32$

\begin{tabular}{|c|c|c|c|c|}
\hline & Paranoid & Compulsive & Depressive & Dramatic \\
\hline \multicolumn{5}{|l|}{ EQ } \\
\hline Entire Scale & -.018 & $-.318 *$ & $-.587 * *$ & $-.412 *$ \\
\hline Empathy & -.034 & $-.255^{*}$ & $-.353^{*}$ & $-.263 *$ \\
\hline Reflect & -.116 & $-.284 *$ & $-.617 * *$ & $-.398 *$ \\
\hline Relate & -.103 & -.114 & $-.586 * *$ & $-674 * *$ \\
\hline Control & -.141 & $-.398 *$ & $-.536 * *$ & $-.423 *$ \\
\hline \multicolumn{5}{|l|}{ TL } \\
\hline Entire Scale & -.038 & -.129 & $-.544 * *$ & -.079 \\
\hline Intellec & -.058 & -.228 & $-.598 * *$ & -.170 \\
\hline Influence. & -.073 & -.210 & $-.376^{*}$ & -.076 \\
\hline Inspire & -.125 & -.089 & $-.368 *$ & -.232 \\
\hline Consid.. & -.227 & -.059 & $-.381 *$ & -.131 \\
\hline Job Satisfaction & $-.350 *$ & -.094 & $-.766 * *$ & -.017 \\
\hline Outcome & -.044 & -.155 & $-.558 * *$ & -.194 \\
\hline
\end{tabular}


Table 5

Bivariate Correlations of Neurotic Leadership Factors with Factors of Emotional Intelligence, Transformational Leadership, Job Satisfaction, and Perceived Leadership Effectiveness for Agency Four.

$\mathbf{N}=21$

\begin{tabular}{lllll}
\hline & Paranoid & Compulsive & \multicolumn{1}{c}{ Depressive } & Dramatic \\
\hline EQ & & & & \\
Entire Scale & -.258 & $-.540^{* *}$ & $-.545^{* *}$ & $-.394^{*}$ \\
$\quad$ Empathy & -.023 & $-.523^{* *}$ & $-.545^{* *}$ & $-.322^{*}$ \\
Reflect & -.221 & $-.351^{*}$ & $-.470^{*}$ & $-.488^{*}$ \\
Relate & -.158 & $-.590^{* *}$ & $-.492^{*}$ & -.250 \\
Control & $-.528^{* *}$ & $-.494^{*}$ & $-.416^{*}$ & -.244 \\
TL & & & & \\
Entire Scale & $-.339^{*}$ & $-.453^{* *}$ & $-.409^{* *}$ & $-.409 * *$ \\
Intellec & -.241 & -.222 & $-.384^{*}$ & -.244 \\
Influence. & -.159 & -.222 & $-.378^{*}$ & $-.413^{*}$ \\
Inspire & $-.327^{*}$ & $-.403^{*}$ & $-.512^{* *}$ & $-.556^{* *}$ \\
Consid.. & $-.383^{*}$ & $-.602^{* *}$ & $-.596^{* *}$ & $-.351^{*}$ \\
& & & & \\
Job Satisfaction & $-.526 * *$ & $-.663^{* *}$ & $-.553^{* *}$ & $-.383^{*}$ \\
Outcome &.$- .352^{*}$ & $-.486^{* *}$ & $-.559^{* *}$ & $-.329 *$ \\
\hline
\end{tabular}

${ }^{*} \mathrm{p} \leq .05 \quad * * \mathrm{p} \leq .00$

Table 6

Bivariate Correlations of Neurotic Leadership Factors with Factors of Emotional Intelligence, Transformational Leadership, Job Satisfaction, and Perceived Leadership Effectiveness for Agency Five

$\mathbf{N}=29$

\begin{tabular}{|c|c|c|c|c|}
\hline & Paranoid & Compulsive & Depressive & Dramatic \\
\hline \multicolumn{5}{|l|}{ EQ } \\
\hline Entire Scale & $-.407 *$ & $-.303^{*}$ & $-.523 * *$ & -.123 \\
\hline Empathy & $-.323 *$ & -.125 & -.182 & -.011 \\
\hline Reflect & $-.328 *$ & $-.298 *$ & $-.431 * *$ & -.211 \\
\hline Relate & -.397* & -.056 & $-.354^{*}$ & -.028 \\
\hline Control & $-.296^{*}$ & $-.400 *$ & $-.632 * *$ & -.108 \\
\hline \multicolumn{5}{|l|}{ TL } \\
\hline Entire Scale & $-.516 * *$ & $-.447 * *$ & $-.634 * *$ & $-.266^{*}$ \\
\hline Intellec & -.241 & -.173 & $-.323^{*}$ & -.027 \\
\hline Influence. & $-.500 * *$ & -.163 & $-.322 *$ & -.061 \\
\hline Inspire & $-.473 * *$ & $-.570 * *$ & $-.555 * *$ & $-.302 *$ \\
\hline Consid.. & $-.572 * *$ & $-.339 *$ & $-.694 * *$ & $-.405 *$ \\
\hline Job Satisfaction & -.236 & $-.533 * *$ & $-.771 * *$ & $-.264 *$ \\
\hline Outcome & $-.437 * *$ & $-.486 * *$ & $-.640 * *$ & -.217 \\
\hline
\end{tabular}




\section{Discussion}

The results of this study strongly allude to the idea that there are organizational dynamics that are specific to each agency that are moderating the relationships between neurotic leadership style and transformational leadership, leader emotional intelligence, employee job satisfaction, and employee perceived leadership effectiveness. Most professional organizations have historically advocated the suppression of emotions in management. A ubiquitous belief is that emotions interfere with rational behavior. Highly bureaucratic structures found in most formal organizations are a manifestation of this assumption. Thus, the so-called emotionless administrative structures of industrial society reflect many of the characteristics of neuroses (i.e., compulsive). In other words, organizational structure, in and of itself, contains purposive processes that generate and maintain neurotic behavior. It could be said that law enforcement agencies comparatively speaking, would fall very high on a continuum of bureaucratic structure. They are very adamant about being rule and procedure oriented while simultaneously condoning emotions. Their paramilitary structure also places high emphases on hierarchical relationships, (i.e., staff and command) which in turn, suppress individual initiative and creativity. This of course is reminiscent of the depressive neurotic orientation. In short, law enforcement agencies contain some intrinsic neurotic organizational characteristics that make them particularly sensitive to the variables explored within this present study. However, the agencies included within this study vary according to not only organizational alignment and work routines, but also the type of communities served, size, and political climate. These differences are probably the reasons for varying statistical results revealed within this study. This study did not measure factors related to organizational processes or structure and therefore could not empirically examine how these influence the investigated relationships. However, we can comment on some of the demographic differences and those subjectively gleaned while administering the survey.

Agency One in comparison to the other agencies perhaps contains the most dynamic, dramatic, and least rule oriented work processes. It is a gang squad unit charged with the responsibility for drug enforcement within a large city. As the commander of the unit stated, given the unpredictable nature of the work officers cannot rely on standardized police procedures as reminiscent of traditional police precincts. Officers, who work in pairs or triads are most often performing their duties independent of supervisory monitoring and feedback. Interpersonal relationships between themselves and their supervisor are much less relevant than that found in the other agencies within this study. This could in turn account for the absence of significant correlations found among the leadership factors. Parsimoniously 
stated, supervision is not as relevant within the workflow in this type of work environment as compared to the others.

Agency Two, on the other hand, is located within the same law enforcement department as Agency One. However, it is a traditional large city precinct, conducting "typical” law enforcement routines where rules and supervision are much more utilized and relevant. This could account for it's revealing a much higher number of significant relationships than Agency One.

Agency Four consists of data collected from several "stations" of a relatively large county sheriff department. These stations cover a large expanse of geography and are for the most part are isolated from one another as well as from central administration. The geographical proximity of these stations has created a situation where central administration relies heavily on bureaucratic rules and procedures for accomplishing organizational control. Several officers made comments about how the bureaucracy within this agency stifles their creativity and that management was very "constricting". Subsequently, officer turnover is very high within this agency. These conditions make leadership behavior and job satisfaction very relevant to officers. This may account for the very strong correlations found between the NL factors and job satisfaction and perceived leadership variables within this agency.

In sum, the findings of this study indicate that the concept of neurotic leadership is indeed empirically relevant to organizational analyses. More importantly, the results strongly allude to the need for conducting research that systematically integrates social forces of organizations to psychodynamic processes. Isolated psychoanalytic or social interpretations of organizational behavior are inadequate for explaining the complexity of organizational dynamics (Fineman, 1993). As Domaglski (1999) states;

"Emotions, to be sure, do not emerge in isolation and they are not merely inner phenomena. They have objects, and they occur within some context...

Neglected in many psychological accounts are the social and cultural

dimensions of emotion. This is a particularly telling gap for organizational theorists since organizational structures, processes and practices are socially created and sustained.” (pp 840-841).

This statement is particularly relevant within the context of recent police shootings within the United States. It is highly conceivable that emotional intelligence among police officers and victims (or the lack thereof) is a core factor underlying these unfortunate events.

As an exploratory study, this present study was adequate in delineating some aspects of the correlation landscape of neurotic leadership. 
Our future research on neurotic research will attempt to incorporate various situational factors of the organization. It will also be useful to include different type of organizations within the study. A study for example that included medical, manufacturing, and educational type organizations within the same study would greatly improve upon its explanatory power in terms of organizational and social factors. Specific organizational factors may include:

1. Level of information and workflow uncertainty

2. Job design of employees

3. Degree of work process formalization

4. Organizational culture and climate (of organization and specific work units)

5. Supervisory span of control

\section{References:}

Ashforth, B. E., \& Humprhey, R. H. (1995). Emotion in the workplace: A reappraisal.

Human Relations, 38, 9-125.

Bass, B., \& Avolio, B. (1994). Improving Organizational effectiveness through transformational leadership. Thousand Oaks, CA: Sage.

Caruso, D., Mayer, J., \& Salovey, P. (2002). Emotional intelligence and emotional leadership. In: Riggio, R.;\& Murphy, S. (Eds.) Multiple Intelligences and Leadership. (pp. 55-74). Mahwah, NJ: Lawrence Erlbaum Associates, Inc.

Cssey, D., \& Mayer, J. (2000). Emotional intelligence: What the research says. Educational Leadership, 58 (3). 14-18.

Czander,W. (1993). The Psychodynamics of Work and Organizations: Theory and Practice. New York: Guilford Press.

DeBoard, R. (1978). The Psychoanalysis of Organizations: A Psychoanalytic approach to Behavior in Groups and Organizations. London: Tavistock Publications.

Domagalski, Theresa A. (1993), Emotion in organizations: Main currents. Human Relations. 52, 6. 833-852.

Fineman, S. (1993) Emotions in Organizations. London. Sage Publications. Flam, H. (1993). Fear, loyalty and greedy organizations. In S. Fineman (Ed.)Emotion in organizations. London: Sage Publications. 58-75

George, J. (2000). Emotions and leadership: The roles of emotional intelligence. Human Relations. 53 (8) 1027-1055.

Goleman, D. A. (1995). Emotional intelligence. New York: Bantom Books. Kets DeVries, M. FR ., \& MILLER, D. (1985) Narcissism and leadership: An object relations perspective. Human Relations. 38(6), 583-601

Kets de Vries, M.FR., \& Balazs, K. (1999). Transforming the mind-set of the 
organization: A clinical perspective. Administration \& Society, 30(6), 640675.

Kets de Vries, M.FR., \& Miller, D. (1984). The neurotic organization. San Francisco: Jossey-Bass.

Hirschhorn, L. (1990). The workplace within: Psychodynamics of organizational life. Boston: MIT Press.

Kelly, G. A. The psychology of personal constructs. (1991). New York: John Wiley.

Kets de Vries, M. FR. \& Miller, D. (1986). Personality, culture, and organization. Academy of Management Review. 11(2), 266-279.

Kets de Vries, M. FR. (1989). What's playing on the organizational theater? Collusive relationships in management. Human Relations. 32, (6), 745-772.

Kets de Vries, M.FR. (1991). Organizations on the couch: Clinical perspectives on organizational behavior and change. San Francisco: JosseyBass.

Mayer, J., \& Salovey, P. (1990). Emotional intelligence. Imagination, Cognition and Personality, 9, 185-211.

Mead, G., H. (1934). Mind, self, and society. Chicago, IL: University of Chicago Press.

Miller, D., Kets de Vries, M.ER., \& Toulouse, J. M. (1982). Top executive locus of control and its relationship to strategy making, structure, and environment. Academy of Management Journal, 25, 237-253.

Motamedi, K. (2006). Seven neurotic styles of management. Graziadia Business Review, 9 (4).

Neumann, J. E. \& Hirschorn, L. (1999). The challenge of integrating psychodynamic and organizational theory. Human Relations, 52, 6.

Sievers, B. (1999) Psychotic organization as a metaphoric frame for the socioanalysis of organizational and interorganizational dynamics. Administration and Society 31, (5) 58-616.

Stacy, R. (2005). The activity of leading in organisations: The reflective and the neurotic. Mt. Eliza Business Review 7 (2). 10-16.

\section{APPENDIX A}

\section{Neurotic Leadership Style Scale}

\section{Paranoid factor}

1. My supervisor uses his/her subordinates to find out what is "going on around

here.

2. My supervisor does not trust his/her employees

3. My supervisor is very secretive about things.

4. My supervisor creates an atmosphere of apathy among employees 


\section{Compulsive factor}

1. My supervisor strictly adheres to rules and regulations in my department.

2. My supervisor appears to be obsessed with controlling people.

3. A person's rank and status are very important to my supervisor.

4. My supervisor is the type of person who wants to analyze every little thing

before making a decision.

\section{Depressive factor}

1. My supervisor does not allow officers to "think out of the box"

2. My supervisor insists upon managing according "to the book".

3. My supervisor asks officers for suggestions on how to improve things around here.

4. My supervisor is not open to new ideas from his/her employees.

\section{Dramatic factor}

1. My supervisor is overly concerned with impressing others.

2. My supervisor appears to have a real craving for excitement.

3. My supervisor is the type of person who likes to draw attention to herself/himself.

4. My supervisor is a very emotional person. 